Editorial

\title{
City Planning and Green Infrastructure: Embedding Ecology into Urban Decision-Making
}

\author{
Paul Osmond ${ }^{1, *}$ and Sara Wilkinson ${ }^{2}$ \\ ${ }^{1}$ School of Built Environment, University of New South Wales, Sydney, NSW 2052, Australia; \\ E-Mail:p.osmond@unsw.edu.au \\ 2 School of Built Environment, University of Technology Sydney, Sydney, NSW 2007, Australia; \\ E-Mail: sara.wilkinson@uts.edu.au \\ * Corresponding author
}

Submitted: 22 December 2020 | Published: 26 January 2021

\begin{abstract}
Green infrastructure (GI) includes an array of products, technologies, and practices that use natural systems-or designed systems that mimic natural processes - to enhance environmental sustainability and human quality of life. Gl is the ultimate source of the ecosystem services which the biotic environment provides to humanity. The maintenance and enhancement of GI to optimise the supply of ecosystem services thus requires conscious planning. The objective of this thematic issue is to publish a cross-section of quality research which addresses how urban planning can contribute to the conservation, management, enhancement, and creation of GI in the city. The terms of reference include the technical, economic, social, and political dimensions of the planning/GI nexus. Here we offer a brief overview of the articles published in this collection, and consider where policy, planning, and design relating to urban GI may be heading in the future.
\end{abstract}

\section{Keywords}

biophilia; ecosystem services; green infrastructure; habitability; sustainability; urban design; urban ecology

\section{Issue}

This editorial is part of the issue "Urban Planning and Green Infrastructure" edited by Paul Osmond (University of New South Wales, Australia) and Sara Wilkinson (University of Technology Sydney, Australia).

(C) 2021 by the authors; licensee Cogitatio (Lisbon, Portugal). This editorial is licensed under a Creative Commons Attribution 4.0 International License (CC BY).

\section{Introduction}

Urban green infrastructure (GI) has been described variously as comprising a cross-city network of greenery, or a more loosely defined assemblage of diverse green elements such as parks, domestic gardens, street trees, and green roofs and walls. Here we apply a broad definition, adopted from a recent project to develop an evidence base for embedding ecology into urban decisionmaking: $\mathrm{GI}$ is "an adaptable term used to describe an array of products, technologies and practices that use natural systems - or designed systems that mimic natural processes - to enhance environmental sustainability and human habitability (quality of life)" (Davies et al., 2017, p. 31). The operative words here are 'to enhance sustainability and habitability.' If we acknowledge the city as human habitat (Moudon, 1997), then sustainability and habitability represent core objectives for urban planning, from city-wide scale to the neighbourhood and to individual buildings.

To pose the question from a different angle, $\mathrm{Gl}$ is the ultimate source of the ecosystem services which the biotic environment provides to humanity. These include supporting services, necessary for the production of all other ecosystem services; provisioning services, products obtained from ecosystems; regulating services, benefits derived from the regulation of ecosystem processes; and cultural services, the nonmaterial benefits people obtain from ecosystems (Millennium Ecosystem Assessment, 2005). Urban GI is a subset of the above, 
incorporating both the restrictions inherent in being circumscribed by built form, and the particular benefits necessary to enhance urban quality of life and ecosystem health. The maintenance and enhancement of GI to optimise the supply of ecosystem services for the city thus requires conscious planning, from room to region (Beatley, 2011).

The objective of this thematic issue is to publish a cross-section of quality research which addresses how urban planning can contribute to the conservation, management, enhancement, and creation of GI in the city. The terms of reference include, but are not limited to, the technical, economic, social, and political dimensions of the planning/GI nexus.

\section{Overview of This Issue}

Building up or spreading out (Mahtta, Mahendra, \& Seto, 2019), and combinations thereof, represent the options to accommodate urban growth-which itself is a given, as the rural-urban population balance shifts increasingly towards the city dweller. The first two articles in this issue examine strategies for integrating urban green space with the densifying city, although from different perspectives. Erlwein and Pauleit (2021) note the supply of urban green space is often at cross purposes with increasing demand for housing. Their article investigates the interaction between densification and the availability of green space from the perspective of summer heat stress, via a set of eight hypothetical densification scenarios. Application of the microscale urban climate software ENVI-Met to model these scenarios in Munich, Germany, demonstrates that preserving existing trees has the greatest impact on outdoor thermal comfort. The authors conclude that protection of mature trees during urban redevelopment projects will become more urgent in a climate constrained world, alongside mobility strategies for slowing the proliferation of car parks, a major cause of tree removal. The second density-focused article, from Bush, Ashley, Foster, and Hall (2021), similarly underlines the challenge of retaining and maximising urban greenery in densifying cities. The authors, from Melbourne, Australia, note an increasing focus on policy mechanisms for integrating $\mathrm{Gl}$ into the private realm. They report on a participatory and transdisciplinary research project which informed the creation of a 'Green Factor' tool for application to building development proposals in their city.

As well as policy mechanisms and cross-disciplinary technical capacity, availability of adequate resources is critical to the establishment and long-term maintenance of urban Gl. Cavada, Bouch, Rogers, Grace, and Robertson (2021) point out the difficulties involved in securing such resources, arguing that generally people and organisations take steps to allocate resources when they can see value accruing to them. Their article describes a case study relating to a woodland in Birmingham, UK, where stakeholders came together to identify value-generating opportunities for their own organisations within the framework of a socialenterprise business model. The authors report that while stakeholders can identify opportunities, limitations due to communication, time, and methodology can constrain the business model, highlighting the importance of social-enterprise entrepreneurs as catalysts and long-term enablers.

The fourth article in this thematic issue, by Matsler, Miller, and Groffman (2021), likewise emphasises the social, ecological, financial, and political challenges involved in urban GI implementation. The authors discuss comparative case studies of $\mathrm{Gl}$ development in Portland and Baltimore, USA, through the lens of an integrative 'Social, Ecological and Technological Systems' (SETS) analysis. They point out that this approach can complement standard planning processes by shedding light on potential trade-offs. The SETS 'eco-techno' spectrum thus "becomes a platform to explore the institutional knowledge system dynamics of Gl development" (Matsler et al., 2021, p. 49), identifying gaps and promoting solutions.

Building capacity around policy, planning, design, and management of GI demands human as well as institutional and capital resources. Noting that professional bodies have highlighted the need for spatial planners to understand and implement urban GI, Frank, Flynn, Hacking, and Silver (2021, p. 63) ask what kind of specialised knowledge planners may need "and moreover by whom and how GI knowledge and competencies may be conveyed?" They found that the status quo relies heavily on continuing professional education and ad hoc opportunities in higher education, leading to a fragmented knowledge base and limited theoretical foundations. Frank et al. (2021, p. 63) conclude that a "systematic inclusion of green infrastructure knowledges" in existing planning curricula is necessary to facilitate effective urban $\mathrm{Gl}$ implementation.

'Doing less bad' is clearly necessary, but certainly not sufficient for the transition to sustainable urbanism. The final article in this collection, by Thompson and Newman (2021), focuses on the concept of regenerative cities. Such cities, they explain, rely on eco-efficiencies, the circular economy, and net positive energy and water management to deal with issues such as climate change. Thompson and Newman (2021) also reference an ecological approach to urban planning and design. Their article acknowledges the tensions between regenerative ('pro-density') and ecological ('anti-density') approaches and focuses on how combining GI with biophilic urbanism can help to reconcile these paradigms to achieve both regenerative and ecological outcomes.

\section{Conclusions}

The overall conclusions from the articles featured in this thematic issue is the overriding and increasing importance of good quality GI. The articles feature research 
undertaken in the northern and southern hemispherese.g., Europe, Australia, and North America-which is testament to the global significance of the topic. In 2020, humankind has experienced the Covid-19 pandemic, with most people working from home and restricted from going out for extended periods and limited to travelling only a few kilometres from home. This substantial change of lifestyle has increased the importance, consciousness, and relevance of GI globally. People are much more aware of local parks and green space as places for safe interaction with nature and other people, albeit at a distance.

This issue is themed around evidence for embedding ecology into decision-making. Four essential stages are recognized, which are to conserve, manage, enhance, and create (Davies et al., 2017). There are five key ways in which we can deliver these essential stages. First, in policy we should protect. Protecting existing GI, particularly urban tree canopy, avoids losses that invariably takes years to recover. Well drafted planning policy is an effective means of protection. Second, and again emerging from a policy framework, is the development and adoption of tools such as Melbourne's Green Factor tool. These tools provide a robust approach for stakeholders to develop and adopt transparent benchmarks. From these benchmarks, management, enhancement, and creation of $\mathrm{Gl}$ is possible. The third key conclusion is the need to value $\mathrm{Gl}$, and to communicate and educate the community about the various social, economic, and environmental values of $\mathrm{Gl}$ and their respective benefits. The outcomes of education and communication are increased requests for $\mathrm{Gl}$ and appreciation of its values. The fourth conclusion is the vital role of planners and professional bodies in raising awareness, designing and implementing policies, and updating and broadening education programs to reflect the vital role of GI in sustainable, liveable, resilient urban development. Through their efforts it will be possible to increase delivery of Gl. Finally, the concept of regenerative design is posited, whereby $\mathrm{Gl}$ is a vital ingredient to deliver urban development with positive $\mathrm{Gl}$ and its associated benefits of better air quality, increased habitat for biodiversity, biophilic engagement of human populations, moderation of the urban heat island, attenuation of stormwater flow, and where placed near or on buildings, reductions in energy used in heating and cooling. In summary, the articles provide ample evidence for embedding ecology into decision-making to deliver the improved GI-rich urban developments which are desperately needed.

So, where to in the future? The term 'megatrends' has propagated through both the academic and popular literature since the publication of John Naisbitt's (1982) book of that name. It is worth a brief excursion into potential megatrends affecting urban GI: Some of these are addressed in this collection of articles, some are not. Coronavirus has underscored the salutogenic (Antonovsky, 1979) function of urban Gl, in terms of both physical and mental health. Whether contributing to stress reduction or facilitation of active transport, rapid urbanisation will ensure this aspect continues to expand. And as our cities grow, the abundant potential of urban agriculture as a Gl type is becoming increasingly evident. The rising importance of digital technologies such as GIS, remote sensing, big data, and the internet of things allow us to conserve, manage, enhance, and create $\mathrm{Gl}$ and ever more efficiently and effectively integrate it into our urban human habitat. Further, as we grasp the challenge of dwindling natural resources and the need for circularity to replace linearity in economic management, the application of life cycle thinking to urban GI-supported by the above digital technologies-will underpin application of new methods to enable the transition from sustainable to regenerative policy, planning, and practice. Last but certainly not least will be the increasing role of $\mathrm{Gl}$ in cooling our overheating cities.

\section{Acknowledgments}

We gratefully acknowledge the help and support of the Urban Planning editorial staff in preparing this thematic issue.

\section{Conflict of Interests}

The authors declare no conflict of interests.

\section{References}

Antonovsky, A. (1979). Health, stress and coping. San Francisco, CA: Jossey-Bass Publishers.

Beatley, T. (2011). Biophilic cities: Integrating nature into urban design and planning. Washington, DC: Island Press.

Bush, J., Ashley, G., Foster, B., \& Hall, G. (2021). Integrating green infrastructure into urban planning: Developing Melbourne's green factor tool. Urban Planning, 6(1), 20-31.

Cavada, M., Bouch, C., Rogers, C., Grace, M., \& Robertson, A. (2021). A soft systems methodology for business creation: The Lost World at Tyseley, Birmingham. Urban Planning, 6(1), 32-48.

Davies, P., Corkery, L., Nipperess, D., Barnett, G., Bishop, M., Hochuli, D., . . . Wilkinson, S. (2017). Urban ecology: Theory, policy and practice in New South Wales, Australia (Urban ecology renewal investigation project). Sydney: National Green Infrastructure Network.

Erlwein, S., \& Pauleit, S. (2021). Trade-offs between urban green space and densification: Balancing outdoor thermal comfort, mobility, and housing demand. Urban Planning, 6(1), 5-19.

Frank, A. I., Flynn, A., Hacking, N., \& Silver, C. (2021). More than open space! The case for green infrastructure teaching in planning curricula. Urban Planning, 6(1), 63-74.

Mahtta, R., Mahendra, A., \& Seto, K. C. (2019). Build- 
ing up or spreading out? Typologies of urban growth across 478 cities of 1 million+. Environmental Research Letters, 14(12), 124077.

Matsler, A. M., Miller, T. R., \& Groffman, P. M. (2021). The eco-techno spectrum: Exploring knowledge systems' challenges in green infrastructure management. Urban Planning, 6(1), 49-62.

Millennium Ecosystem Assessment. (2005). Ecosystems and human well-being: General synthesis. Washington, DC: Island Press. Retrieved from https://www. millenniumassessment.org/documents/document. 356.aspx.pdf

Moudon, A. V. (1997). Urban morphology as an emerging interdisciplinary field. Urban Morphology, 1(1), 3-10.

Naisbitt, J. (1982). Megatrends: Ten new directions transforming our lives. New York, NY: Warner.

Thompson, G., \& Newman, P. (2021). Green infrastructure and biophilic urbanism as tools for integrating resource efficient and ecological cities. Urban Planning, 6(1), 75-88.

\section{About the Authors}

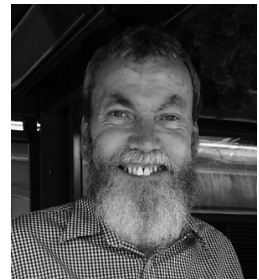

Paul Osmond is Associate Professor in the UNSW School of Built Environment, which he joined in 2010 following several years as the University's Environment Manager. Previously, he worked in environmental management, landscape, and urban design. Paul has qualifications in applied science, environmental management, and landscape design. He is a Certified Environmental Practitioner, Registered Environmental Auditor, Green Star Accredited Professional, and Fitwel 'Ambassador.' His publications include 34 journal articles, 45 refereed conference papers, nine book chapters and one book.

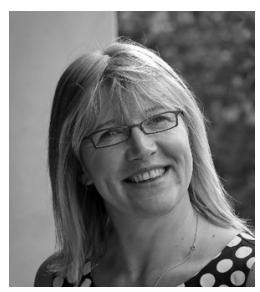

Sara Wilkinson is a Chartered Building Surveyor and Australia's first female Professor of Property. Her transdisciplinary research program sits at the intersection of sustainability, urban development, and transformation, with a focus on green cities and preparing urban environments for climate change. Sara works with academics and industry partners in engineering, science, health, and business. She has written nine books, 30 book chapters, 33 research reports, 58 refereed journal and 105 refereed conference papers, and eight keynote presentations. 